\title{
TURBULENT VELOCITY AND TEMPERATURE PROBABILITY DENSITY FUNCTIONS IN THE AMAZONIAN SURFACE BOUDARY LAYER
}

Leonardo Deane de Abreu Sá*, Maurício José Alves Bolzam, Fernando Manuel Ramos, Camilo Rodrigues Neto, Reinaldo Roberto Rosa

DCM - LAC / INPE

São José dos Campos, São Paulo, Brazil.

\section{RESUMO}

Neste trabalho é apresentado um modelo estatístico para a distribuição de incrementos de velocidade de vento e temperatura dos dados de turbulência medidos na camada limite superficial atmosférica sobre a floresta amazônia, em uma torre de micrometeorological instalada na Reserva Rebio-Jaru ( $10^{\circ} 04^{\prime} \mathrm{S}$; $61^{\circ} 56^{\prime} \mathrm{W}$ ) durante o LBA (Large Scale Biosphere Atmosphere Experiment in Amazonia), campanha da estação úmida. Os dados foram medidos usando um anemômetro sônico 3D Campbell e um termômetro Campbell de resposta rápida localizados a uma altura de $66 \mathrm{~m}$ (a copa da floresta tem uma altura média de $35 \mathrm{~m}$, mas

- Corresponding author: Leonardo Deane de Abreu Sá, DCM - INPE, Av. dos Astronautas, 1758, CEP 12901.970, São José dos Campos, SP, Brazil, Email: leo@met.inp.br 
algumas árvores podem alcançar a altura de $45 \mathrm{~m}$ ), amostrados a uma taxa de $60 \mathrm{~Hz}$. O objetivo desta investigação é detectar propriedades não extensivas do campo turbulento em um ambiente peculiar. Para isto, foi calculada a função de densidade de probabilidade (PDF) para os incrementos da velocidade de vento $\mathrm{V}_{\mathrm{r}}(\mathrm{x})=\mathrm{V}(\mathrm{x})-\mathrm{V}(\mathrm{x}+\mathrm{r})$ (e incrementos de temperatura) em diferentes escalas de comprimento $r$. Os resultados preliminares mostram alguma evidência de que o modelo termoestatístico não extensivo proposto por Tsallis (1988) fornece uma teoria simples para explicar o comportamento estatístico da turbulência desenvolvida. Também foi investigada a relação entre intermitência e não extensividade usando um parâmetro simples q, a partir da termoestatística de Tsallis. Os resultados para os sinais turbulentos de velocidade do vento medidos ao nível de $66 \mathrm{~m}$ concordaram bem com o modelo de Tsallis, mas para a temperatura mostram alguma discrepância com relação ao modelo proposto. São apresentadas discussões físicas para explicar os resultados.

\section{ABSTRACT}

We present a statistical model for the distribution of increments of wind velocity and temperature of turbulence data measured in the atmospheric surface layer above the Amazonian forest, on a micrometeorological tower in Rebio-Jaru Reserve (10 04' S; 610 56' W) during LBA (Large Scale Biosphere Atmosphere Experiment in Amazonia) wet season campaign. The data were measured using 3D Campbell sonic anemometer and a Campbell fast response thermometer located at a height of $66 \mathrm{~m}$ (the forest canopy has a mean height of $35 \mathrm{~m}$; but some of the higher tree branches may reach the height of $45 \mathrm{~m}$ ), at a sampling rate of $60 \mathrm{~Hz}$. The goal of this investigation is to detect noextensivity properties of the turbulent field in such a peculiar environment. To do this we calculate the probability density function (PDF) for wind velocity increments $V_{r}(x)=V(x)-V(x+r)$ (and 
temperature increments) at different length scales $r$. The preliminary results show some evidence that the nonextensive thermostatistics modelling proposed by Tsallis (1988) provides a new and simple framework for explaining the statistical behavior of fully developed mechanical turbulence. We also investigate the relationship between intermittency and nonextensivity using a single parameter $\mathrm{q}$, from Tsallis thermostatistics. The results of the wind velocity turbulent signals measured at the level of $66 \mathrm{~m}$ show a very good agreement with the Tsallis model but the temperature signals show some discrepancy with respect to the proposed model. Physical discussions are proposed to explain our results.

\section{INTRODUTION}

Turbulence is a very important phenomenon in the transport processes in flows having high Reynolds number, as it is the case for most of the situations in the atmospheric surface boundary layer (Monin and Yaglom, 1971; Tennekes and Lumley, 1972).

Some significant progresses have already been made on the description of many of the statistical characteristics of the turbulent processes (Frisch, 1995; Sreenivassan and Antonia, 1997). An important component of them is expreessed by the hypotheses formulated by Kolmogorov in 1941 (K41: Monin and Yaglom, 1971) and in 1962 (K-62: Kolmogorov, 1962; Kraichnan, 1991; Frisch, 1991; Van Atta, 1991) which allows to explain many fenomenological aspects of the spectral characteristics of the developed turbulence (Van Atta, 1991). In spite of this, they fail in providing solid theoretical basis to explain some impotant features of the turbulence such as the small scale distribution of the dissipation rate of turbulent kinetic energy, and the intermittency (Kraichnan, 1974; Lumley, 1992; Nelkin, 1992; Katul et al., 1994). 
One of the methods to study the statistical laws of the turbulence in its smaller scales is based on the analyses of the probability density functions (PDFs) of the differences between turbulent variables separated by a distance $r$, such as the longitudinal wind speed component, $u$, the vertical component, w, and the temperature, T, (Antonia et al., 1984; Yakhot, 1989; Kraichnan, 1991; Castaing et al., 1990; Katul et al., 1994; Chu et al., 1996). These studies provide a better understanding of the nature of intermittency phenomenon in the small scale of the turbulence, and help to explain some of the observed differences between the fluctuations fields of wind speed and scalars. Besides, they permit obtaining better information about the distribution of dissipation rate of turbulent kinetic energy.

PDFs are calculated through the statistics of differences of speeds (or other turbulent variables) at different scales $r$. As in many physical systems that depend on the dynamic evolution of a great number of sub systems coupled in a non linear way, the turbulent energy cascade makes the statistical moments of the variables behave according to a potency law in $r$. For high values of the Reynolds number, there is a huge separation between the scale of production of turbulent kinetic energy (integral scale, L) and the scale of dissipation (microscale of Kolmogorov, $\eta$ ). Besides, in the greatest scales, PDFs are usually normal but, far away from the integral scale length, they are strongly non-Gaussian (Kevlahan and Vassilikos, 1994), which express an important characteristic of the intermittent phenomenon. Although several authors have tried to determine the best fitted function with respect to turbulence PDFs (Sinai and Yakhot, 1989; Castaing et al., 1990; Kraichnan, 1991; Frisch, 1995; Sreenivasan and Antonia, 1997), there is, still, a lot of disagreement concerning the best fitted function (Castaing et al., 1990, Chu et al., 1996), particularly for temperature PDFs (Antonia et al., 1984; Balachandar and Sirovich, 1991; Jaberi et al., 1996).

In this work, a comparative study of modeling of the statistical behavior of the developed turbulence will be presented based on the Rev. Ciência e Natura, Dispersion Process: 195 - 215 , 2000. 
nonextensive thermodynamics procedure proposed by Tsallis (1988). We used data which were measured above the Amazon Forest in Rondônia, under two different atmospheric stability conditions: a stable one (for night situations) and other unstable (for strong convection situations). So, were investigated the PDFs of variables $w, u$ and $T$.

\section{THEORY}

Based on the scaling properties of multifractals, Tsallis (1988) has proposed a generalization of Boltzmann-Gibbs thermostatistics by introducing a family of generalized nonextensive entropy functionals $S_{q}[p]$ with a single parameter q. These functionals reduce to the classical, extensive Boltzmann-Gibbs form as $q \rightarrow 1$.

Optimizing $S_{q}[p]$ subject to appropriate constraints (Tsallis et al, 1995), we obtain the distribution

$$
p_{q}(x)=\left[1-\beta(1-q) x^{2}\right]^{1 /(1-q)} / Z_{q}
$$

The appropriate normalization factor, for $1<q<3$, is given by

$$
Z_{q} \equiv\left\{\left[\frac{\beta(q-1)}{\pi}\right]^{1 / 2} \frac{\Gamma(1 /(q-1))}{\Gamma((3-q) / 2(q-1))}\right\}^{-1}
$$

In the limit of $q \rightarrow 1$, we find the Gaussian distribution. The above distribution would provide one of the simplest and most accurate model for handling the PDF problem. To show this, we stay in the context of fully 
developed turbulence $\left(x \equiv V_{r}\right)$. From equation (1), we can easily obtain the second moment

$$
\left\langle v_{r}^{2}\right\rangle=\frac{1}{\beta(5-3 q)},
$$

and the flatness coefficient (kurtosis)

$$
K_{r}=\frac{3(5-3 q)}{(7-5 q)}
$$

\section{EXPERIMENTAL DATA}

The above mentioned turbulence statistical model was tested with data obtained during an intensive micrometeorological campaign which is part of the wet season LBA (Large Scale Biosphere Atmosphere Experiment in Amazonia) project. The experiment was carried out during the months of January to March 1999. Measurements were made simultaneously at three different heights in a micrometeorological tower located in the Biological

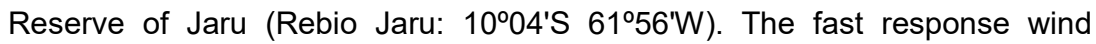
speed measurements, sampled at a $60 \mathrm{~Hz}$ frequency, were made using threedimensional sonic anemometers (Campbell Scientific Inc, model CSAT-3-L60) and three thermometers (Campbell Scientific Inc, model CA27).

During the experiment, the state of the atmosphere was characterized by the existence of strong convective activity in the diurnal period with isolated rain events. Also, during the experimental period, the ZCAS (Convergence Zone of Southern Atlântico) was active above the brazilian State of Rondônia. The experimental site was characterized by the existence of reasonable fetch conditions. The area where the tower was built 200 Rev. Ciência e Natura, Dispersion Process: 195 - 215 , 2000. 
is surrounded by the Amazon Forest in a radius of at least $800 \mathrm{~m}$ around the tower. The topography of the area was not totally homogeneous, since at the southern and eastern sides of the tower there are small hills with heights of some dozens of meters. More information on the variability pattern of the main micrometeorological variables during the period of the experiment is presented by Sá et al. (2000). Culf et al. (1996) presented a discussion of the micrometeorological characteristic of the Rebio Jaru site area during the dry season.

\section{RESULTS AND DISCUSSION}

In this work we used turbulent temperature and vertical and longitudinal wind velocity data which were separated in two main classes according to the two main atmospheric stability regimes: unstable and stable.

The PDFs were obtained using statistical calculations which started from relationships such as $\Delta u_{r}=u(x)-u(x+r)$, for the the variables $u, w$ e $T$. This provides the difference between two measurements of a same variable, separated by a distance $r$.

In spite of the fact that this is a controversial subject, (Kaimal et al., 1972; Srenivasan and Antonia, 1997), we accepted the assumption of frozen turbulence which is expressed by the well known Taylor's Hypothesis (Gledzer, 1997) to obtain length distance intervals from time intervals: $r=\bar{U} \Delta t$, (in which $\bar{U}$ is the mean velocity of the flow which forces the measurement instruments). This procedure has been used successfuly by authors as Katul et al (1994) to analyse inertial subrange turbulent fluctuations of micrometeorological variables.

To arrive to a better understanding of the environmental processes which eventually disturb the PDFs' shapes, we have studied data from unstable and stable conditions data in separated analyses. This 
procedure is particularly suited for Amazonian forest turbulence studies as was demonstrated by Fitzjarrald and Moore (1990) and Fitzjarrald et al. (1990) in their studies about spectral characteristics above and below canopy under stable and unstable conditions, respectively.

This section is divided in two parts: the first concerns the unstable regime and the second concerns the stable one. In both analyses we discuss the main characteristics of the PDFs of wind velocity and temperature fluctuations

In order to better contrast departures from Gaussian distributions in all variables, the PDFs are normalized using the standard deviation of the measured flow variable as proposed by Chu et al. (1996). We perform, also, calculations of the third moment (skewness) and the fourth moment (kurtosis or flatness factor) to better understand the intermittency effects on the PDFs in homogeneous and isotropic turbulence. This seems particularly important for the PDFs of the scalar variables which depict a clear tail-shape which is less evident in the PDFs of velocity fields (Chu et al., 1996).

\subsection{Unstable Regime}

To carry out the discussion concerning PDFs in unstable regime we present in table 1 calculations of skewness and kurtosis of variables $\mathrm{u}, \mathrm{w}$ and $\mathrm{T}$, for each one of the following time-intervals:

$$
\Delta t=0.2,2,20,200 \mathrm{~s} \text {. }
$$

To do this we started from the equations (1)-(3) and used kurtosis to fit the Tsallis distribution in each one of the time intervals already mentioned.

Under the unstable regime all experimental results for $u$ and $w$ are in good agreement with Tsallis' theoretical model, as shown in figures 1 and 2 .

202 Rev. Ciência e Natura, Dispersion Process: 195 - 215 , 2000. 


\begin{tabular}{|c|c|c|c|c|c|}
\hline & & $\Delta t=0.2 s$ & $\Delta t=2 s$ & $\Delta t=20 s$ & $\Delta t=200 s$ \\
\hline Comp. u & SKEWNESS & 0.0239 & -0.1382 & 0.3695 & 0.2269 \\
\hline Comp. u & KURTOSIS & 8.5180 & 6.6942 & 4.0291 & 2.6083 \\
\hline Comp. w & SKEWNESS & 0.1239 & 0.7037 & 0.1137 & 0.5309 \\
\hline Comp. w & KURTOSIS & 9.3302 & 8.6836 & 5.4066 & 4.1413 \\
\hline Temp. & SKEWNESS & -0.0408 & 0.0075 & 0.1970 & -0.2945 \\
\hline Temp. & KURTOSIS & 13.8663 & 8.7726 & 4.2830 & 3.1052 \\
\hline
\end{tabular}

Table 1: Values of the statistical properties of $u, w$ and $T$ variables in each analysed time interval (Data from 13:05 Hs to 13:35 Hs).

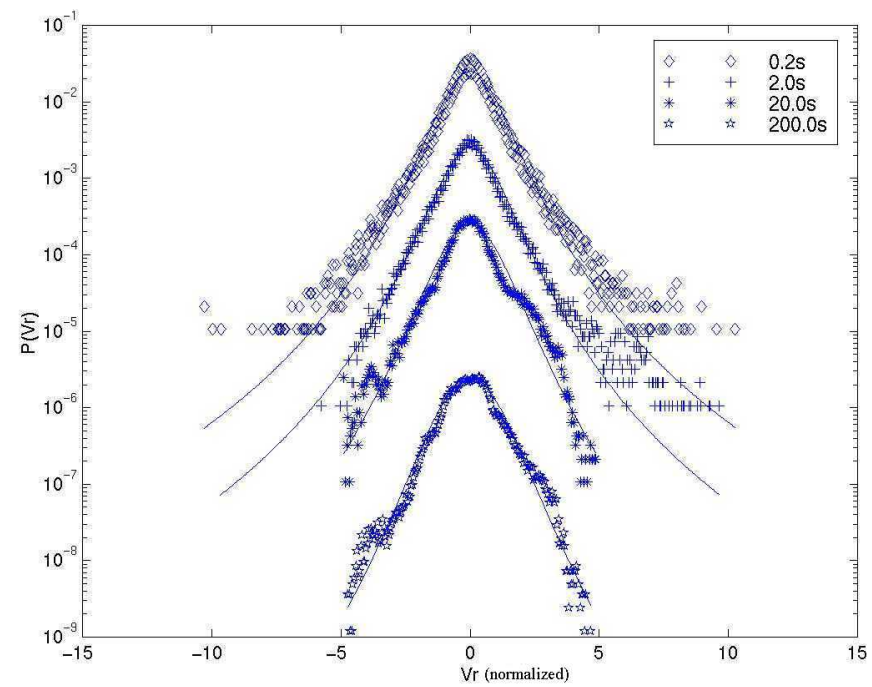

Figure 1: Probability density functions of vertical wind velocity $w$, from data measured from 13:05 to 13:35 Hs (local time). The experimental PDFs were obtained for $\Delta t=0.2,2,20,200 s$. The theoretical PDFs are in solid lines. 
A physical phenomenon which could introduce some discrepancy on the experimental PDFs' shapes when compared to the theoretical ones is probably due to the presence of coherent structures (Högström and Bergström, 1996) at the scales from 20 to 200s. As is pointed out by these authors, coherent structures are particularly active in flows near forest canopies where the vertical wind profile has a inflexion point, as is the case of Amazon forest. It is interesting to stress that Gannabathula et al.(2000) analysing turbulent data measured at the Rebio-Jaru experimental site have detected coherent structures near the scale of 200 s by means of wavelet transform signal analysis, (this for $u, w$ and $T$ variables). So, this could explain the anomalous PDFs shapes we have obtained, even for $u$ signals (particularly for the $200 \mathrm{~s}$ scale). Figure 2 shows u-PDF in 13:05-13:35 Hs, local time.

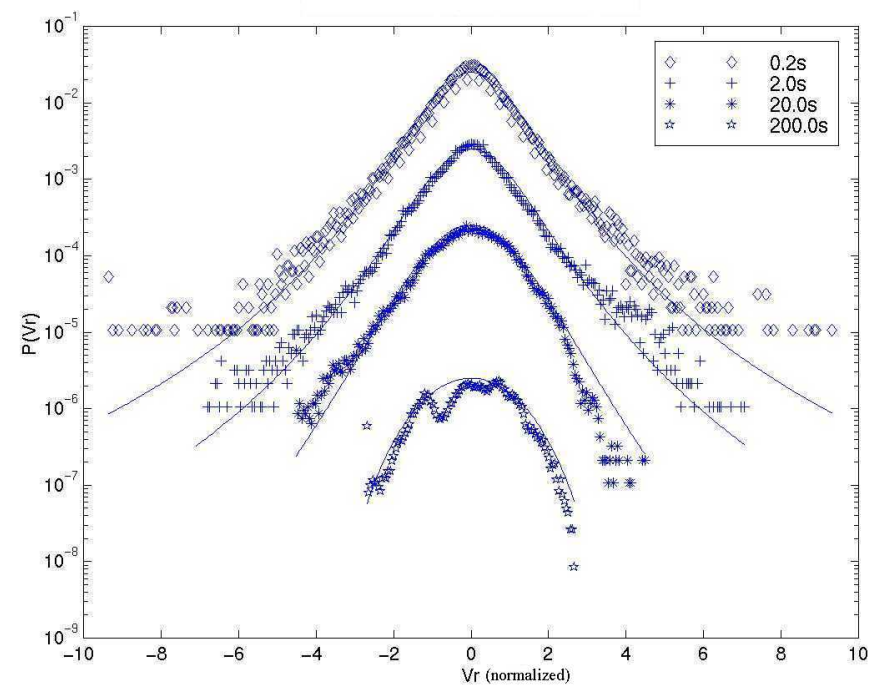

Figure 2: As figure1, except it is for $u$ wind velocity component. 
In results for temperature, PDF curves presented a more skewed shape when compared to the wind velocity (figure 3) and so, they have shown some discrepancy with respect to the theoretical function. According to Chu et al. (1996) this could be due to "like-ramp" coherent structures effects which have been detected in turbulent scalar signals by authors such as Antonia et al. (1984). These kind of patterns were also observed on the shape of fast response temperature data measured at RebioJaru Site tower.

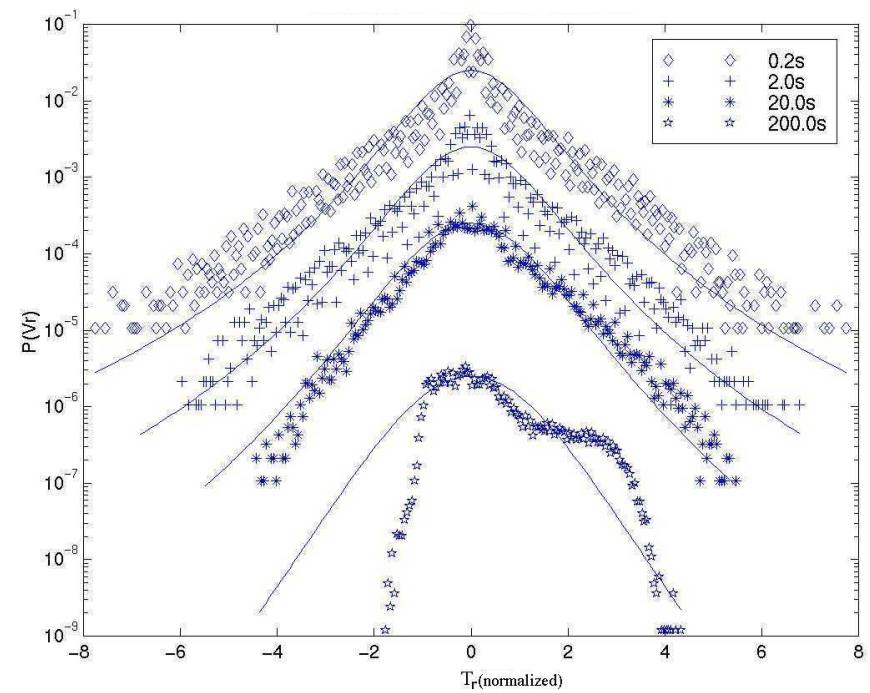

Figure 3: As figure1, except it is for temperature to the 13:05 Hs.

\subsection{Stable Regime}

In this regime, we have also observed very good agreement between the experimental results and the PDF model of the wind components $u$ and $w$, even for $P\left(V_{r}\right)$ values located far from $V_{r}=0$, diversely from the 
results obtained under unstable conditions. This suggests that some anomalous PDFs patterns obtained far from $V_{r}=0$ are probabily due to the action of mesoscale organized motions on the wind flow which generate updrafts and downdrafts motions over the experimental site and disturb in some way the shape of the PDF curves. This kind of distorsion in PDFs shapes, induced by convective motions was already detected by Baerentsen and Berkowics (1984). The best agreement between the theoretical and the PDFs of $u$ and $w$ was observed at 5:00 Hs local time data (even for the $200 \mathrm{~s}$ $\Delta t$ interval) just in a situation in which stability condition is the strongest. To show the shapes of PDF under stable conditions we present figure 4 (for $u$ ), figure 5 (for $w$ ) and 6 (for $T$ ) in which are depicted both theoretical and experimental PDFs. The wind velocity experimental PDFs show a good agreement with the theoretical densities. This is probabily due to the fact that convective motions are absent of the nocturnal surface layer. Regarding the temperature PDFs under stable conditions, two main aspects of the results could be stressed, concerning the agreement between the experimental data and the theoretical curves:

1) The fit of temperature PDF is best under stable conditions when compared to unstable ones;

2) The fit of temperature PDF is not as good as the $u$ and $w$ PDFs.

These results probabily have emphasized that there are some physical differences which determine distinctly the velocity and temperature PDFs. Some discussion about the physical differences between the character of temperature and wind velocity turbulent fluctuations is made by Monin and Yaglom (1971) which have shown that in the atmospheric surface layer, the universal functions calculated from nondimensional statistical parameters of the turbulent fluctuations of the wind speed are not exactly the same as scalar. 
One important question to be mentioned is the possible Gaussian character of the PDFs curves. According to Chu et al. (1996), temperature PDFs would be Gaussian under stable conditions. Indeed, on Amazon forest data this feature was observed more clearly at $5: 00 \mathrm{Hs}$ (local time), when the atmosphere reaches its state of maximum stability. However, this was not true for curves obtained under unstable conditions.

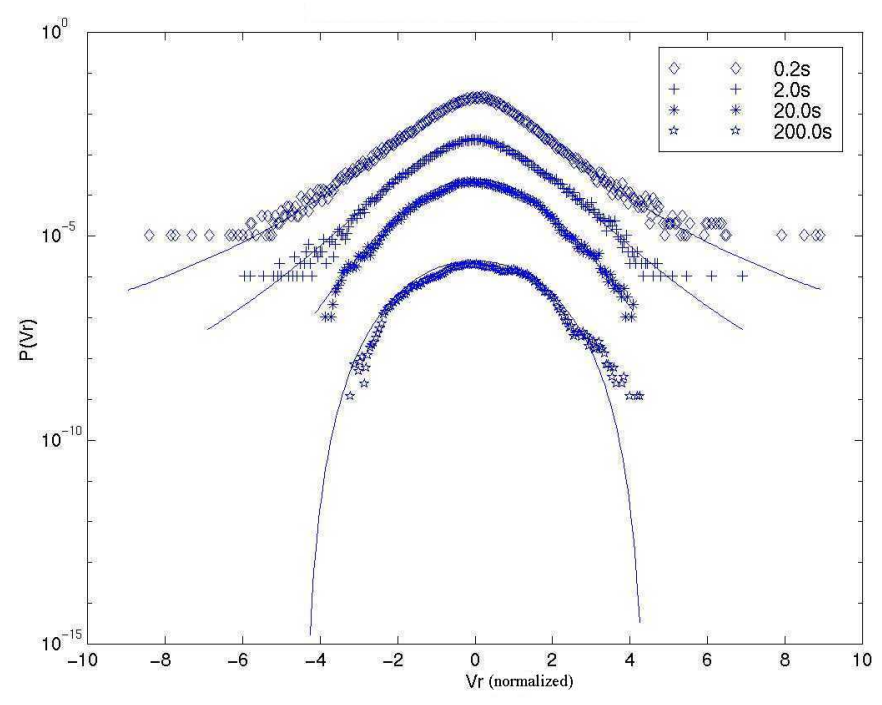

Figure 4: As figure 1, except it is for $u$ wind velocity component to the $05: 05 \mathrm{Hs}$ 


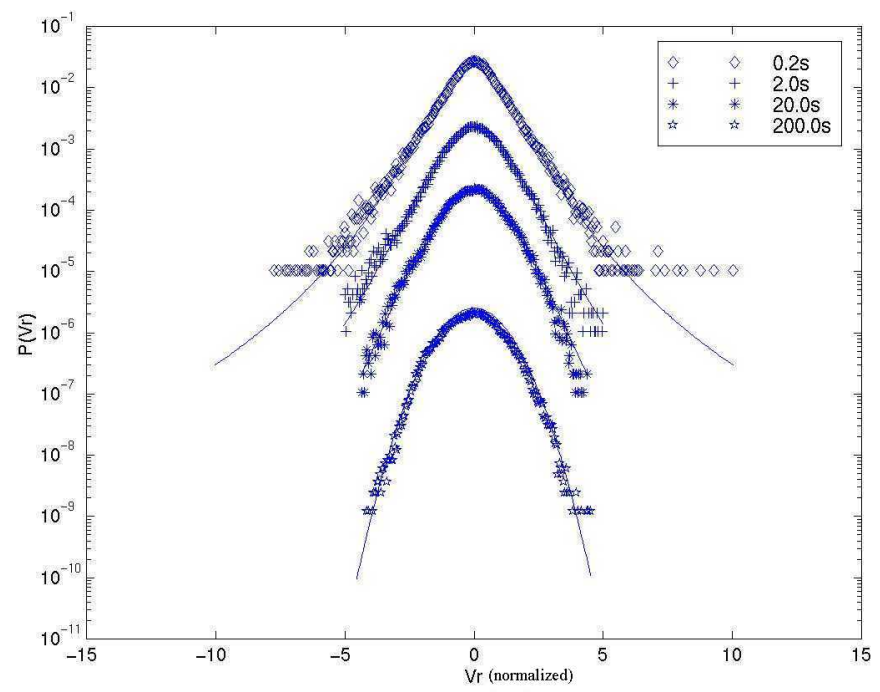

Figure 5: As figure 1, excepts it is for $w$ wind velocity component to the 05:05 Hs.

We observed an other important distinction among the results under stable and unstable regimes for $u, w$ and $T$ variables. Under stable regime all values obtained for kurtosis are lower than the ones obtained for unstable conditions, as we can observe at the table 2 . This is probably due to the fact that intermittency is more active during diurnal situations, when unstable regime prevails. Under this situation, motions with organized flow such as updrafts and downdrafts (Fitzjarrald et al., 1990) or coherent structures (Katul et al., 1994) could determine the enhancement of intermittent fluctuations. In stable regime, as Chu et al (1996) pointed out, the lower kurtosis values can be associated to effects of (eventual) gravity waves, phenomena already observed near the canopy of Amazon forest (Fitzjarrald and Moore, 1990).

208 Rev. Ciência e Natura, Dispersion Process: 195 - 215 , 2000. 


\begin{tabular}{|c|c|c|c|c|c|}
\hline & & $\Delta t=0.2 s$ & $\Delta t=2 s$ & $\Delta t=20 s$ & $\Delta t=0.2 s$ \\
\hline u comp. & SKEWNESS & -0.1041 & 0.0213 & 0.0529 & 0.0910 \\
\hline u comp. & KURTOSIS & 5.5184 & 4.0534 & 3.2271 & 2.9241 \\
\hline w comp. & SKEWNESS & -0.0434 & -0.1473 & -0.1331 & 0.0999 \\
\hline w comp. & KURTOSIS & 6.1239 & 4.2432 & 3.6030 & 3.0530 \\
\hline Temp. & SKEWNESS & -0.2422 & -0.4296 & -0.0560 & -0.1726 \\
\hline Temp. & KURTOSIS & 7.5630 & 5.4723 & 2.9908 & 2.9533 \\
\hline
\end{tabular}

Table 2: Values of the statistical properties of $u, w$ and $T$ variables for each analysed scale (Data from 05:05 Hs to 05:35 Hs).

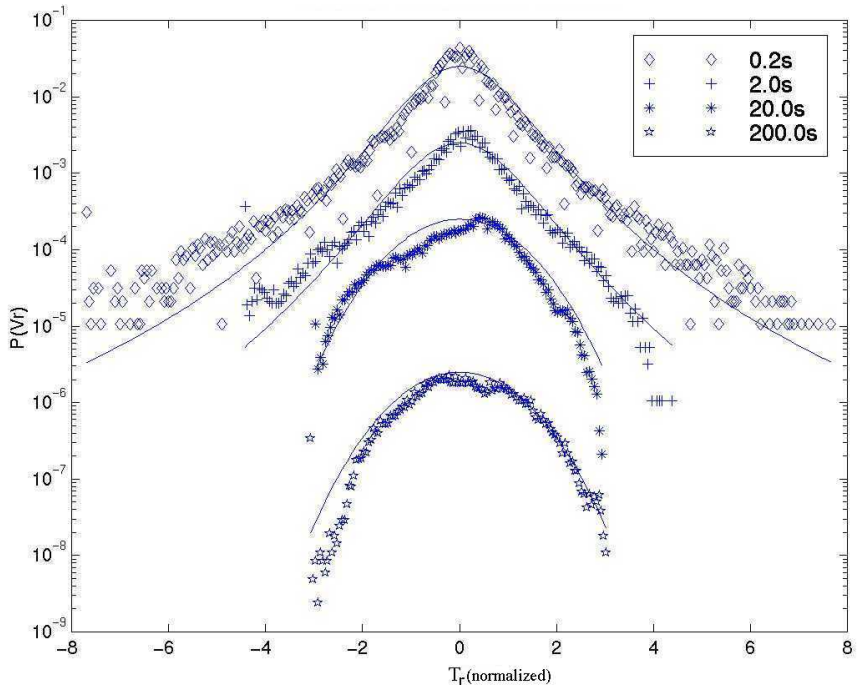

Figure 6: As figure 1, except it is for temperature at 05:05 Hs.

Rev. Ciência e Natura, Dispersion Process: 195 - 215 , 2000. 


\section{CONCLUSIONS}

We have demonstrated sucessfully the applicability of Tsallis nonextensive thermostatistics in modelling the statistical behavior of fully developed atmospheric turbulence in the inertial subrange.

The probability density functions were calculated with data measured above and inside the Amazon forest during the wet season Experiment LBA Campaign.

To perform the statistical fittings, we used wind velocity components $\mathrm{u}$ and $\mathrm{w}$ and temperature data under unstable and stable conditions, for each one of the following time intervals $\Delta t=0.2,2,20,200 \mathrm{~s}$.

The best fitted results have been obtained from wind velocity data under stable conditions. This is probably due to the fact that coherent structures and other organized motions in the surface boundary layer such as updrafts and downdrafts are stronger during diurnal situations, when unstable conditions are dominant.

Temperature PDF functions are not so well fitted against theoretical curves than wind velocity ones. This is probably due to the fact that temperature fluctuations present some physical characteristics which are different than the ones of the wind velocity field. 


\section{ACKNOWLEDGEMENTS}

This work is part of The Large Scale Biosphere-Atmosphere Experim,ent in Amazonia (LBA) and was supported by FAPESP/Brazilprocess 1997/9926-9 (Dr. Maria Assunção F. S. Dias Coordinator). Thanks are also given to Mr. João L. Esteves (INCRA/Ji-Paraná) and Mr. C. Brandão (IBAMA/Ji-Paraná) and to all the participants of LBA Rebio Jaru wet season campaign. Fernando M. Ramos acknowledges the support from CNPq, Camilo R. Neto the fellowship from FAPESP and Mauricio J. A. Bolzam the fellowship from CAPES. Also, we whould like to thank to Mr. Paulo R. de Aquino Arlino for technical support in LBA, and to Mr. Alexandre Nowossad for revision of the text. 


\section{REFERENCES}

Antonia, R. A.; Hopfinger, E. J.; Gagne, Y.; Anselmet, F., Temperature structure functions in turbulent shear flows, Physical Review A, v. 30, n. 5, p. 2704-2707, Nov. 1984.

Baerentsen, J. H. and Berkowicz, R. Monte Carlo Simulation of Plume Dispersion in the Convective Boundary Layer, Atmospheric Environment, v. 18, n. 4, p. 701-712, 1984.

Balanchandar, S. and Sirovich, L. Probability distribution function in turbulent convection. Physics of Fluids A, v. 3, n. 5, p. 919-927, May 1991.

Castaing, B.; Gagne, Y.; Hopfinger, E. J. Velocity probability density functions of high Reynolds number turbulence. Physica D, v. 46, p. 177-200, 1990.

Chu, C. R.; Parlange, M. B.; Katul, G. G.; Albertson, J. D. Probability density functions of turbulent velocity and temperature in the atmospheric surface layer, Water Resources Research, v. 32, n. 6, p. 1681-1688, Jun. 1996.

Culf, A. D.; Esteves, J. L.; Marques Filho, A. O. and Rocha, H. R. Radiation, temperature and humidity over forest and pasture in Amazonia, In: Amazonian Deforestation and Climate, C. A. Nobre, J.H.C. Gash, J.M. Roberts and R.L. Victoria Eds., Wiley: 175-191, Chichester, 1996.

Fitzjarrald, D. R. and Moore, K. E. Mechanisms of Nocturnal Exchange Between the Rain Forest and the Atmosphere, Journal of Geophysical Research, v. 95, n. D10, p. 16839-16850, Sep. 1990.

Fitzjarrald, D. R.; Moore, K. E.; Cabral, O. M. R.; Scolar, J.; Manzi, A. O.; Sá, L. D. A. Daytime Turbulent Exchange Between the Amazon Forest and the Atmosphere, Journal of Geophysical Research, v. 95, n. D10, p. 1682516838, Sep. 1990.

Frisch, U. From global scaling, à la Kolmogorov, to local multifractal scaling in fully developed turbulence, In: Turbulence and Stochastic Processes: Kolmogorov's Ideas 50 Years On, J.C.R. Hunt, O. M. Phillips and D. 
Williams Eds., Proceedings of the Royal Society of London A: 434, 8999, London, 1991.

Frisch, U. Turbulence, Cambridge University Press, 296 pp., Cambridge, 1995.

Gannabathula, S. S. D. P.; Castro JR., W. E.; Sá, L. D. A.; Vittal Murty, K. P. R.; Wavelet Analysis of Coherent Structures Above and Within the Amazon Rain Forest, Preprints of the 15th Conference on Hydrology, TRMM Hydrology, $80^{\text {th }}$ Annual Meeting of the American Meteorological Society: 375-378, American Meteorological Society, Long Beach, CA, 9-14 January 2000.

Gledzer, E. On the Taylor hypothesis corrections for measured energy spectra of turbulence, Physica D, v. 104, p. 163-183, 1997.

Högström, U. and Bergström, H. Organized Turbulence in the Near-Neutral Atmospheric Surface Layer, Journal of the Atmospheric Sciences, v. 53, n. 17, p. 2452-2464, Sep. 1996.

Jaberi, F. A.; Miller, R. S.; Madnia, C. K.; Givi, P. Non-Gaussian scalar statistics in homogeneous turbulence, Journal of Fluid Mechanics, v. 313, p. 241-282, Apr. 1996.

Kaimal, J. C.; Wyngaard, J. C.; Izumi, Y.; Coté, O. R. Spectral Characteristics of surface layer turbulence, Quarterly Journal of the Royal Meteorological Society, v. 98, n. 417, p. 563-589, July 1972.

Katul, G. G.; Parlange, M. B.; Chu, C. R. Intermittency, local isotropy, and non-Gaussian statistics in atmospheric surface layer turbulence, Physics of Fluids, v. 6, n. 7, p. 2480-2492, July 1994.

Kevlahan, N. K.-R. and Vassilicos, J. C. The space and scale dependencies of the self-similar structure of turbulence, Proceedings of the Royal Society of London A, v. 447, p. 341-363, 1994.

Kolmogorov, A. N. A refinament of previous hypotheses concerning the local structure of turbulence in a viscous incompressible fluid at high Reynolds number, Journal of Fluid Mechanics, v. 13, p. 82-85, 1962. 
Kraichnan, R. H. On Kolmogorov's inertial-range theories, Journal of Fluid Mechanics, v. 62 (part. 2), p. 305-330, 1974.

Kraichnan, R. H. Turbulent cascade and intermittency growth, In: Turbulence and Stochastic Processes: Kolmogorov's Ideas 50 Years On, J.C.R. Hunt, O. M. Phillips and D. Williams Eds., Proceedings of the Royal Society of London A: 434: 65-78, London 1991.

Lumley, J. L. Some Comments on Turbulence, Physics of Fluids, v. A4, n. 2 , p. 203-211, Feb. 1992.

Monin, A. S. and YAglom, A. M. Statistical Fluid Mechanics: Mechanics of Turbulence, MIT-Press, Cambridge, MA, 1971, 769 p.

Nelkin, M. In What Sense Is Turbulence an Unsolved Problem?", Science, v. 255, n. 5044, p. 566-570, 1992.

Sá, L. D. A. et al. General aspects of the Rebio-Jaru amazon forest micrometeorological tower LBA wet season campaign with some of its preliminary results. Preprints of the $15^{\text {th }}$ Conference on Hydrology, TRMM Hydrology: 369-372, 80 $0^{\text {th }}$ Annual Meeting of the American Meteorological Society, Long Beach, CA, 9-14, January 2000.

Tennekes, H. and Lumley, J. L. A First Course in Turbulence, MIT-Press, Cambridge, MA, 1972, $300 \mathrm{p}$.

Sinai, Ya. G. and Yakhot, V. Limiting probability distribution of a passive scalar in a random velocity field. Physical Review Letters, v. 63, n. 18, p. 1962-1964, Oct. 1989.

Sreenivasan, K. R. and Antonia, R. A. The Phenomenology of Small-Scale Turbulence, Annual Review of Fluid Mechanics, v. 29, p. 435-472, 1997. Tsallis, C. Possible generalization of Boltzmann-Gibbs statistics. Journal of Statistical Physics, v. 52, n. 1-2, 1988.

Tsallis, C., Levy, S. V. F., Souza, A. M. C.; Maynard, R. Statistical-mechanical foundation of the ubiquity of Levy distributions in nature. Physical Review Letters., v. 75, p. 3589-3593, 1995. 
Van Atta, C. Local isotropy of the smallest scales of turbulent scalar and velocity fields, In: Turbulence and Stochastic Processes: Kolmogorov's Ideas 50 Years On, J.C.R. Hunt, O. M. Phillips and D. Williams Eds., Proceedings of the Royal Society of London A: 434, 139-147, London, 1991.

Vassilicos, J.C. Turbulence and intermittency. Nature, v. 374 , n. 6521 , p. $408-$ 409, 1995.

Yakhot, V.; She, Z.-S.; Orszag, S. A . Deviations from the classical Kolmogorov theory of the inertial range of homogeneous turbulence. Physics of Fluids, v. A1, n. 2, p. 289-293, Feb. 1989.

Zhu, Y.; Antonia, R. A.; Hosokawa, I. Refined similarity hypotheses for turbulent velocity and temperature fields. Physics of Fluids, v. 7, n. 7, p. 1637-1648, July 1995. 
216 Rev. Ciência e Natura, Dispersion Process: 195 - 215 , 2000. 